\title{
Universal health coverage of five essential health services in mothers before and after the Haiti 2010 earthquake: a retrospective cohort study using difference-in-difference
}

Naoki Hirose ( $\nabla$ naoki-hirose@hiroshima-u.ac.jp )

Hiroshima University

Sanmei Chen

Hiroshima University

Koichiro Shiba

Harvard T.H Chan School of Public Health

Crystal L Patil

University of Illinois at Chicago

MD Moshiur Rahman

Hiroshima University

\section{Yoko Shimpuku}

Hiroshima University

\section{Research Article}

Keywords: Universal Health Coverage, earthquake, Haiti, reproductive health, difference-in-difference

Posted Date: February 23rd, 2022

DOI: https://doi.org/10.21203/rs.3.rs-1384286/v1

License: (c) (i) This work is licensed under a Creative Commons Attribution 4.0 International License.

Read Full License 


\section{Abstract \\ Background}

In January 2010, Haiti was hit by a 7.0-magnitude earthquake. The impact of the earthquake on Universal Health Coverage in mothers remains unclear. This study explores the association between the 2010 Haiti earthquake and access to the five quality essential health services among women who gave birth in the two years before and after the earthquake.

\section{Methods}

From the Sixth Demographic and Health Survey in Haiti, we extracted data for women aged 15-49 who had reported a live birth in the two years before and after the 2010 Haiti earthquake. We used differencein-difference analyses for antenatal care, delivery care, and vaccination and multivariate logistic regression analyses for family planning and malaria prevention to assess the impact of the acute physical damage of the earthquake on these mothers' access to quality essential health services.

\section{Results}

Mothers who had not suffered acute physical damage were more likely to live in rural areas and had less education and household wealth. The difference-in-difference and multivariate logistic regression analyses did not show strong evidence of any significant association between acute physical damage and access to quality health services. However, after the earthquake, access to quality health services deteriorated for both mothers with and without acute physical damage $(-5.6 \%$ and $-6.2 \%$ for antenatal care, $-6.5 \%$ and $0 \%$ for delivery care, and $-9.5 \%$ and $-13.1 \%$ for vaccination, respectively).

\section{Conclusions}

The earthquake adversely affected mothers' access to quality essential health services regardless of their exposure to acute physical damage. Mothers in rural areas who avoided such damage might also have experienced long-term negative effects from the earthquake, which was likely exacerbated by other structural factors such as lower education and economic status.

\section{Introduction}

\section{Background}

Universal health coverage (UHC), endorsed by the World Health Organization (WHO), means that all people receive the quality essential health services that they need without suffering from financial hardship.(1) Since the $58^{\text {th }}$ World Health Assembly resolution in 2005, the importance of UHC has been 
widely recognized, and in 2015 , UHC was counted as one of the United Nations Sustainable Development Goals.(1)

Achieving or sustaining UHC even in the context of the emergency (e.g., a major natural disaster) is imperative to minimizing the suffering related to disrupted access to essential health services, especially for vulnerable populations, such as mothers and infants. (2) For example, a devastating earthquake affects the health system both in the short term and long term. In the short term, it kills people, destroys homes and health facilities, and devastates water and communications supplies. (3) In the long term, it might cause the spread of infectious diseases due to a breakdown of sanitation, high cost to rebuild the health care system, and lack of health care professionals and health supplies.

In January 2010, Haiti was hit by a 7.0-magnitude earthquake, causing an estimated 316,000 deaths and 300,000 injuries, displacing 1.3 million people, and destroying 97,294 houses. (4) Previous studies indicated that some of the essential health services for mothers and babies were disrupted by this devastating earthquake. (5-7) For example, in addition to increase in the infant mortality and child mortality rates, mothers' exposure to this earthquake was associated with multiple adverse health events, including increased risk for intrauterine growth restriction, reduced use of injectables for family planning, and increased unplanned pregnancies. However, previous studies listed above focused on pregnancy and birth outcomes and accessibility to essential health services, but the quality of these health services, a key indicator of UHC, remained unexplored, even though quality is a critical factor in the desired health outcomes. (5-7) Also, these studies focused on limited essential health services in UHC such as family planning, malaria prevention, or vaccination, even though the earthquake might have impacted other essential health services, such as antenatal care and delivery care.

To achieve and sustain UHC even under an emergency like an earthquake, it is critical to identify the weaknesses in the system that cause limited access to quality services for the wide array of essential health services for mothers. In this study, we explored associations between the 2010 Haiti earthquake and the access to quality health services in family planning, antenatal care, delivery care, vaccination, and malaria prevention. We hypothesize that the mothers exposed to acute physical damage from the earthquake had more deteriorated access to quality health services compared to mothers who did not.

\section{Method}

\section{Data source}

We used the Sixth Demographic and Health Survey (DHS) in Haiti, which comprised retrospective data collected after the earthquake for 14,287 women aged $15-49$. The DHS is a nationally representative household survey conducted in more than 85 countries worldwide since 1984. DHS has high response rates (typically more than $90 \%$ ) (8), nationwide coverage, highly quality training for interviewer, and standardized data collection across regions and countries over time. In DHS data collection process, 
trained interview teams visit randomly selected households during the interview period (between January and June 2012 for the Sixth Haiti DHS) and conduct interviews with eligible household members.

We included women who reported a live birth in the two years before and after the 2010 Haiti earthquake (i.e., between January 2008 and June 2012). We included only the latest birth if a woman had multiple births because the DHS collected detailed data on pregnancy or delivery of the latest birth. The women who reported a live birth more than two years before the earthquake were excluded to minimize potential recall bias. We applied additional inclusion and exclusion criteria to make the sub-cohort for each outcome because the mothers' need for health services were different depending on the type of services (Table 1).

\section{Exposure}

We measured the acute physical damage of the earthquake and classified it into two dimensions: household damage and regional damage. Household impact was defined as the housing damage (yes or no) and/or loss of a family member (yes or no) due to the earthquake. If mothers experienced housing damage and/or loss of a family member due to the earthquake, they were defined as having suffered household damage. We measured both based on the retrospective self-report by mothers who answered the Haiti sixth DHS questionnaire. Regional damage was defined as living in the region where $50 \%$ or more of houses had been damaged. This definition was used in the previous study that explored the impact of the 2010 Haiti earthquake on birth outcomes. (7) To the best of our knowledge, there is no established way to define the damage from earthquake to essential health services in low- and middleincome countries. Therefore, we created several definitions of the earthquake damage combining two dimensions of the earthquake impact (household damage and regional damage). First, as a primary definition, mothers who had experienced at least one of household damage or regional damage were defined as the exposed group. Second, mothers who had suffered household damage were defined as exposed regardless of their exposure to regional damage. Third, mothers who had experienced regional damage were defined as exposed regardless of their exposure to household damage. To measure shortterm damage from the earthquake in antenatal care, delivery care, and vaccination, we limited the exposed group to mothers who reported a live birth within six months after the earthquake.

\section{Outcomes}

The outcomes were: access to quality health services in family planning, antenatal care, delivery care, child vaccination, and malaria prevention because these are considered essential health services under UHC (9) and could be calculated using the sixth Haiti DHS datasets. We conducted separate analyses for each health service, and the cohort of each analysis was mothers who needed them. Table 1 presents the definitions of the cohort and the quality health services for each health service. We measured satisfaction 
with access to quality health services by identifying key domains of care measured between January and June 2012, in accordance with the following international guidelines or previous studies: DHS Revising Unmet Need for Family Planning, (10) the WHO family planning guideline of 2018 (11) and antenatal care guideline of 2016 (12), previous studies on antenatal care (13,14), WHO intrapartum care guideline of 2018 (15), WHO immunization guideline of 2020 for vaccination (16), and the DHS report for malaria prevention and treatment. (17) This approach to assessing health service coverage is known as effective coverage (EC), which measures the efforts under $\mathrm{UHC}$ to accurately reflect the access to quality health services, and was developed in response to UHC measuring only access to the health services previously, and not their quality (18). The mothers were judged to be satisfied with the access to quality health services if they could access more domains for each health service than the threshold of 3 out of 4 domains for family planning, 5 out of 8 for antenatal care, 4 out of 7 for delivery care, 4 out of 4 for vaccination, 2 out of 3 for malaria prevention. For example, if the mothers had accessed more than 5 domains in antenatal care, she was considered satisfied with the access to quality health services in antenatal care.

\section{Covariates}

We assessed several individual-level characteristics of mothers: age (continuous variable), smoking status (yes or no), education status (no education, primary, secondary, or higher), urban or rural, region of residence (Aire Metropolitaine/ Reste-Ouest, Artibonite, Camps, Centre, Grand'Anse, Nippes, Nord, Nord-Est, Nord-Ouest, Sud, Sud-Est ), decision maker for health care (not mother or mother), household wealth (poor, middle, rich), alcohol drinking (everyday, time to time, rarely, never), mothers' occupation (not working, non-professional, agricultural, professional), and fathers' occupation (not working, nonprofessional, agricultural, professional).

\section{Statistical analysis}

Mothers' characteristics were described as the mean and SD for continuous variables and as the number and percentage for categorical variables. These characteristics were compared between the earthquake exposed group and the unexposed group stratified by before and after earthquake using Mann-Whitney test for continuous variables and Fisher's exact test for categorical variables.

For antenatal care, delivery care, and vaccination, we used the difference-in-difference (DID) analysis. The DID design requires two differences: the difference in the outcomes comparing after and before the event in the group exposed to the event (A1), and the same difference in the group unexposed to the event (A2). The change in outcomes associated with the event unexplained by the secular trends could be estimated as A1-A2. In our study, the effect of the Haiti 2010 earthquake on EC in each health service was analyzed using the logistic regression model and the equation below: 


\section{logit $\operatorname{Pr}\left[\mathrm{Y}_{\mathrm{i}}=\right.$ Exposure $_{\mathrm{i}}$, Postperiod $\left.i, C_{i}\right]=\beta 0+\beta 1 \times$ Exposure $_{\mathrm{i}}+\beta 2 \times$}

\section{Postperiod $i+\beta 3 \times$ Exposure $\times$ Postperiod $i+\beta 4 \times C_{i}$}

Where (1) Pri is the possibility of experiencing the outcome of interest for participant $i$; (2) Exposure is 1 if the participant $i$ experienced the earthquake; (3) Postperiod $_{i}$ is 1 if the participant $i$ gave birth after the

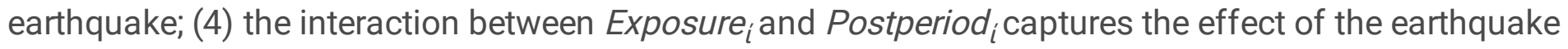
(in the logit scale) on outcomes of interest after excluding the effect of temporal trend on the outcomes; (5) $C_{i}$ is the vector notation of mothers' age and education status.

In the DID analysis, we included mothers' age and education status and did not include other covariates because the latter were measured after the earthquake and were probably affected by it; hence, if they were adjusted, the effect estimate would have been underestimated. To evaluate the validity of the DID design, we examined pre-earthquake tends in the outcomes and assessed the plausibility of the parallel trend assumption.(19) For family planning and malaria prevention, we conducted multivariate logistic regression analysis because, for these health services, DHS did not record the data before the earthquake. In these analyses, we adjusted for variables as in the DID analysis.

For both DID and multivariable logistic regression analyses, we applied a mixed effect model with the random effect of region (11 regions in Haiti). To address potential bias due to missing data, we applied the multiple imputation method in which we used the chained equations to create 10 imputed datasets (mice, or multivariate imputation by chained equations, in R). The estimates from the 10 imputed datasets were then combined using Rubin's rules .(20)

We conducted several sensitivity analyses. First, for the outcome of antenatal care, we excluded births within 10 months after the earthquake because these mothers likely received antenatal care both before and after the earthquake; hence, the outcomes may be misclassified in terms of the temporal relationship with the exposure. Second, we conducted DID and multiple regression analyses with the outcomes in continuous variable (the number of domains where mothers accessed each health service in Table 1) instead of binary variable, considering that the threshold definitions for each outcome would lead to measurement bias due to the misclassification.

All statistical analyses were two-tailed and conducted using R, Version 4.0.3 and Oracle ${ }^{\circledR} \mathrm{R}$ Enterprise, Version 1.4.1 (Oracle, Redwood Shores, CA, USA).

\section{Results}

The final sample included 5703 mothers; 3229 reported a live birth before the earthquake and 1844 reported a live birth after. The earthquake-exposed mothers were more likely to live in urban area, have higher education and household wealth status, and have non-agricultural occupations (Table 2). 
The difference between pre- and post-earthquake access to quality health services was $-5.6 \%$ for mothers without acute physical damage and $-6.2 \%$ in the mothers with such damage in antenatal care, $-6.5 \%$ and $0 \%$ in delivery care, and $-9.5 \%$ and $-13.1 \%$ in vaccination, respectively (Table 3 and Figure 1 ). Also, in almost all components of each essential health service, access to quality health services decreased from pre-earthquake (Supplementary Table 4). Supplementary Figure 2 shows the outcome trend in mothers with/without acute physical damage were parallel before the earthquake for antenatal care, delivery care, and vaccination. Table 3 shows the results of the DID and multivariable logistic regression analyses. In unadjusted and adjusted DID analyses, there was no strong evidence of the associations between the exposure to acute physical damage and access to quality antenatal care, delivery care, and vaccination. Similar results were confirmed in unadjusted and adjusted multivariable logistic regression analyses in family planning and malaria prevention. Supplementary Table 5 shows the results of the additional and sensitivity analyses. We observed similar tendency in all sensitivity analyses.

\section{Discussion}

We conducted this retrospective study to explore the impact of the 2010 Haiti earthquake on quality health services in mothers. Contrary to our hypothesis, we did not observe strong evidence that mothers with acute physical damage from the earthquake experienced lower access to quality health services compared to mothers without it. This may be because the acute physical damage did not cause any negative impact, or the earthquake equally impacted both groups. Because both groups of mothers' access to quality health services was found to have deteriorated in the descriptive analyses (Table 3), the earthquake might have worsened the access to quality health services for mothers with/without acute physical damage.

To the best of our knowledge, this is the first study that shows that mothers without acute physical damage also experienced deterioration of access to quality health services. Previous studies show that mothers exposed to the earthquake were more likely to have adverse reproductive health outcomes compared to unexposed or less exposed mothers. (5-7) This inconsistency may come from the differences in outcome and exposure definitions between these studies. In our study, the outcome of interest was quality of health services while previous studies focused on access regardless of quality. Additionally, for a more comprehensive measurement of earthquake exposure, we combined household and regional damage of the earthquake, while previous studies focused narrowly on living in an area with greater housing damage or displacement.

There could be several explanations for the deterioration of access to quality health services even for mothers with/without acute physical damage. First, long-term structural damage may have adversely affected the access to the quality health services even for mothers who avoided acute physical damage. Well-known long-term structural damages are spread of communicable diseases due to worsened air or water quality, and lack of food safety or sanitation after the earthquake.(21) Indeed, after the 2010 earthquake, Haiti experienced one of the largest cholera outbreaks, causing 600,000 cases and more than 7,000 deaths in the first two years after the earthquake.(22) This outbreak was widespread, including 
rural areas that were far from the epicenter of the earthquake.(23) Haiti's Ministry of Health lost more than 200 staff in the earthquake and a large part of its operating capacity was devastated.(24) Therefore, even though mothers in rural areas could avoid acute physical damage, it was highly likely that they suffered due to the long-term structural damages resulting in deteriorated access to essential health services.

Second, mothers without acute physical damage were relatively more exposed to the long-term structural damages due to pre-existing vulnerabilities. In our study, mothers who did not suffer acute physical damage mainly lived in rural areas and had lower education or wealth status than the exposed mothers. There is evidence that poorer and less educated people are more vulnerable to the disaster.$(25,26)$ Thus in Haiti, the earthquake disproportionately affected poor people in rural areas and worsened their access to quality health services, irrespective of their exposure to acute physical damages.

Third, although mothers with acute physical damage suffered the most (including long-term structural damage), the overall effect could have been mitigated slightly due to the intensive foreign aid and reconstruction efforts in urban areas, compared to mothers without acute physical damage as they were mainly in rural areas.(5)

Our study has several strengths. First, we used the large-scale nationally representative household data, which were constructed with well-established sampling and data collection methods. Second, we applied DID, a statistically robust natural experimental method, which could appropriately consider unmeasured non-time varying confounders. Third, multiple analyses with different definitions of earthquake exposure showed similar tendencies, strengthening the robustness of our results.

Alongside, several limitations should be acknowledged. First, our study targeted mothers in Haiti, and generalizability of our results to mothers in other countries should be carefully interpreted. Second, if mothers suffered other impacts at the same time as the earthquake, the DID method could not appropriately estimate the impact of the earthquake (common shock assumption) .(27) However, an earthquake is a sudden and unexpected event; therefore, we believe there was no common shock that impacted mothers in Haiti at the same time as the earthquake. Third, our definition of the regional impact of the earthquake may have not fully reflected the full impact as it considered only the percentage of housing damage in each area. Damage to health care workers, medical equipment or drug supply, and funds for health care should also be considered for a more accurate measurement of the regional damage.

\section{Conclusion}

The 2010 earthquake negatively affected Haitian women's access to quality essential health services regardless of their exposure to acute physical damage. Furthermore, mothers who avoided acute physical damage of the earthquake may have suffered from the long-term structural damages of the earthquake, which were likely exacerbated by other structural factors such as their lower education and economic status. As part of recovery efforts for UHC in Haiti, government and emergency aid need to pay attention 
not only to mothers who suffered from acute physical damage, but also to mothers who did not but were nonetheless exposed to long-term structural damages and rendered vulnerable.

\section{List Of Abbreviations}

\begin{tabular}{ll} 
Word & Abbreviation \\
\hline Universal Health Coverage & UHC \\
\hline World Health Organization & WHO \\
\hline Demographic and Health Survey & DHS \\
\hline Effective coverage & EC \\
\hline Difference-in-difference & DID
\end{tabular}

\section{Declarations}

\section{Availability of data and materials}

The data that support the findings of this study are available from [U.S Agency for International Development] but restrictions apply to the availability of these data, which were used under license for the current study, and so are not publicly available.

\section{Ethics approval and consent to participate}

The requirement of informed consent from individual participants was waived because of the anonymous nature of the secondary data. DHS has obtained ethical approval from the ICF Institutional Review Board; we obtained the permission from ICF to access the Haiti datasets.

\section{Consent for publication}

All authors can confirm that they have approved the manuscript for submission.

\section{Competing interests}

All authors have no issues relating to journal policies; we declare no competing interests. 


\section{Funding}

This study was funded by the 2021 Satake Foundation. The funding body did not take any roles in the design of the study and collection, analysis, and interpretation of data and in writing the manuscript.

\section{Authors' contributions}

$\mathrm{NH}$ and $\mathrm{YS}$ conceived the study. $\mathrm{NH}, \mathrm{SC}, \mathrm{KS}, \mathrm{CP}, \mathrm{MR}$, and $\mathrm{YK}$ designed the study. $\mathrm{NH}$ conducted the analyses. $\mathrm{NH}, \mathrm{SC}, \mathrm{KS}, \mathrm{CP}, \mathrm{MR}$, and $\mathrm{YK}$ contributed to the interpretation of the results. $\mathrm{NH}$ drafted the manuscript and $\mathrm{SC}, \mathrm{KS}, \mathrm{CP}, \mathrm{MR}$, and $\mathrm{YK}$ critically reviewed the manuscript.

\section{Acknowledgments}

Not applicable

\section{References}

1. World Health Organization, World Bank. Tracking Universal Health Coverage: First Global Monitoring Report. World Health Organization. 2015;86.

2. Clarke L, Le Masson V. Shocks, Stresses and Universal Health Coverage. Overseas Development Institute; 2017.

3. Cartwright C, Hall M, Lee ACK. The Changing Health Priorities of Earthquake Response and Implications for Preparedness: A Scoping Review. Public Health. 2017 Sep;150:60-70.

4. Dube A, Moffatt M, Davison C, Bartels S. Health Outcomes for Children in Haiti since the 2010 Earthquake: A Systematic Review. Vol. 33, Prehospital and Disaster Medicine. Cambridge University Press; 2018. p. 77-88

5. Behrman JA, Weitzman A. Effects of the 2010 Haiti Earthquake on Women's Reproductive Health': A Difference-in-Difference Analysis. Studies in Family Planning. 2016 Mar;47(1):3-17.

6. Chen B, Halliday TJ, Fan VY. The Impact of Internal Displacement on Child Mortality in PostEarthquake Haiti: A Difference-in-Differences Analysis. International Journal for Equity in Health. 2016 Jul 19;15(1).

7. Harville EW, Do M. Reproductive and Birth Outcomes in Haiti before and after the 2010 Earthquake. Disaster Medicine and Public Health Preparedness. 2016;10(1):59-66.

8. Corsi DJ, Neuman M, Finlay JE, Subramanian SV. Demographic and Health Surveys: A profile. International Journal of Epidemiology. 2012;41(6):1602-13.

9. World Health Organization, World Bank. Tracking Universal Health Coverage: 2017 Global Monitoring Report. Washington, DC: World Health Organization; 2017. 
10. Bradley SEK, Croft TN, Fishel JD. DHS Analytical Studies 25: Revising Unmet Need for Family Planning. 2012.

11. World Health Organization. Family Planning - A global handbook for providers 2018 edition. 2018.

12. World Health Organization. WHO Recommendations on Antenatal Care for A Positive Pregnancy Experience. 2016.

13. Hodgins S, D'agostino A. The Quality-Coverage Gap in Antenatal Care: Toward Better Measurement of Effective Coverage. Global Health: Science and Practice. 2014;2(2).

14. Kyei NNA, Chansa C, Gabrysch S. Quality of Antenatal Care in Zambia: A National Assessment. BMC Pregnancy Childbirth. 2012 Dec 13;12.

15. World Health Organization. WHO Recommendations. Intrapartum Care for A Positive Childbirth Experience. 2018.

16. World Health Organization. WHO Recommendations for Routine Immunization.

17. Castle S, Scott R, Mariko S. Malaria prevention and treatment for children under five in Mali: further analysis of the 2012-13 Demographic and Health Survey. DHS Further Analysis Report. 2014;(93):viiipp.

18. World Health Organization; World Bank; Ministry of Health Singapore. Measurement and Monitoring of Universal Health Coverage. 2013.

19. Zhou H, Taber C, Arcona S, Li Y. Difference-in-Differences Method in Comparative Effectiveness Research: Utility with Unbalanced Groups. Health Economics and Health Policy. 2016;14(4):419-29.

20. Rubin DB. Multiple Imputation for Nonresponse in Surveys. New York: Wiley; 1987. 258 p.

21. Nola IA. Earthquakes and Their Environmental, Medical and Public Health Impacts. Salud Publica de Mexico. 2018;60(1):S16-22.

22. Lee EC, Chao DL, Lemaitre JC, Matrajt L, Pasetto D, Perez-Saez J, et al. Achieving Coordinated National Immunity and Cholera Elimination in Haiti Through Vaccination: a Modelling Study. The Lancet Global Health. 2020;8(8):e1081-9.

23. Barzilay EJ, Schaad N, Magloire R, Mung KS, Boncy J, Dahourou GA, et al. Cholera Surveillance during the Haiti Epidemic - The First 2 Years. The New England Journal of Medicine. 2013;368(7):599-609.

24. Amibor P. What Will It Take to Maintain The Maternal and Child Health Gains Made in Haiti Prior to The 2010 Earthquake?: An Analysis of Past Progress, Trends, and The Prospects for The Realization of The United Nations Millennium Development Goals 4 and 5. Maternal and Child Health Journal. 2013 Oct 1;17(8):1339-45.

25. Dayton-Johnson J. Natural Disaster and Vulnerability. OECD Development Center; 2006.

26. Hallegatte S, Vogt-Schilb A, Rozenberg J, Bangalore M, Beaudet C. From Poverty to Disaster and Back: a Review of the Literature. Economics of Disasters and Climate Change. 2020;4(1):223-47.

27. Sasabuchi Y. Introduction to Difference-in-Differences Design. Annals of Clinical Epidemiology. 2021;3(3):74-7. 


\section{Tables}

Table 1. Inclusion and exclusion criteria and definition of each outcome of the health care services 


\begin{tabular}{|c|c|c|}
\hline & Cohort criteria & Outcome definition \\
\hline $\begin{array}{l}\text { ily } \\
\text { Ining }\end{array}$ & $\begin{array}{l}\text { Inclusion criteria (all of the following) } \\
\text { 1. Currently married } \\
\text { 2. 15-49 years old } \\
\text { 3. Currently not pregnant } \\
\text { 4. Does not want another child now or ever } \\
\text { Exclusion criteria (any of the following) } \\
\text { 1. Never menstruated or menstruated before last birth } \\
\text { 2. In menopause or had hysterectomy } \\
\text { 3. Declared infecund } \\
\text { 4. Never had sex } \\
\text { 5. Using modern contraceptive method not related with side } \\
\text { effects (further questions about side effects were not } \\
\text { collected for those methods) }\end{array}$ & $\begin{array}{l}\text { Outcome domains (threshold: } 3 \text { or } \\
\text { more) } \\
\text { 1. Currently using modern } \\
\text { contraceptive methods (IUD, } \\
\text { injectables, implants, or pill) } \\
\text { 2. Informed about the side effects of } \\
\text { these methods } \\
\text { 3. Informed about how to deal with } \\
\text { the side effects } \\
\text { 4. Informed about other family } \\
\text { planning methods }\end{array}$ \\
\hline $\begin{array}{l}\text { natal } \\
\end{array}$ & $\begin{array}{l}\text { Inclusion criteria (all of the following) } \\
\text { 1. } 15-49 \text { years old } \\
\text { 2. Have at least one birth in } 5 \text { years } \\
\text { 3. Birth after } 2008\end{array}$ & $\begin{array}{l}\text { Outcome domains (threshold: } 5 \text { or } \\
\text { more) } \\
\text { 1. First ANC visit in up to } 12 \text { weeks } \\
\text { 2. More than } 4 \text { ANC visits } \\
\text { 3. Blood pressure taken during } \\
\text { pregnancy } \\
\text { 4. Urine sample taken during } \\
\text { pregnancy } \\
\text { 5. Blood sample taken during } \\
\text { pregnancy } \\
\text { 6. Had taken drugs for intestinal } \\
\text { worms during pregnancy } \\
\text { 7. Were informed about signs } \\
\text { suggesting problem in pregnancy } \\
\text { 8. Were given iron tablet during } \\
\text { pregnancy }\end{array}$ \\
\hline $\begin{array}{l}\text { very } \\
\end{array}$ & $\begin{array}{l}\text { Inclusion criteria (all of the following) } \\
\text { 1. } 15-49 \text { years old } \\
\text { 2. Have at least one birth in } 5 \text { years } \\
\text { 3. Birth after } 2008 \\
\text { Exclusion criteria (any of the following) } \\
\text { 1. Child death within } 2 \text { months } \\
\text { 2. Birth after May } 2012 \text { (at least 2-month follow-up period) }\end{array}$ & $\begin{array}{l}\text { Outcome component (threshold: } 4 \text { or } \\
\text { more) } \\
\text { 1. Received health check for mother } \\
\text { after delivery } \\
\text { 2. Received health check for baby } \\
\text { within } 1 \text { hour after delivery } \\
\text { 3. Stayed at health facility after } \\
\text { birth for at least } 24 \text { hours } \\
\text { 4. Receiving the health check for } \\
\text { baby within } 2 \text { months after delivery } \\
\text { 5. Receiving a vitamin A dose in } 2 \\
\text { months after delivery } \\
6 . \text { Ever breastfed } \\
\text { 7. Baby was placed at mother's } \\
\text { breast within } 60 \text { minutes after } \\
\text { delivery }\end{array}$ \\
\hline cination & $\begin{array}{l}\text { Inclusion criteria (all of the following) } \\
\text { 1. } 15-49 \text { years old } \\
\text { 2. Have at least one birth in } 5 \text { years } \\
\text { 3. Birth after } 2008 \\
\text { 4. Child is alive for at least one year } \\
\text { Exclusion criteria (any of the following) } \\
\text { 1. Birth after July } 2011 \text { (at least } 1 \text {-year follow-up period) }\end{array}$ & $\begin{array}{l}\text { Outcome component (threshold: } 4 \text { ) } \\
\text { 1. Child received BCG at once } \\
\text { 2. Child received polio vaccine at } \\
\text { least } 3 \text { times } \\
\text { 3. Child received DPT vaccine at } \\
\text { least } 3 \text { times }\end{array}$ \\
\hline
\end{tabular}




\begin{tabular}{l|l|l|} 
& & $\begin{array}{l}\text { 4. Child received measles vaccine at } \\
\text { once }\end{array}$ \\
\hline aria & Inclusion criteria (all of the following) & $\begin{array}{l}\text { Outcome component (threshold: 2) } \\
1.15-49 \text { years old } \\
\text { 2. Have at least one birth in 5 years } \\
\text { 3. Child is alive } \\
\text { the previous night } \\
\text { 2. Mother slept under the mosquito } \\
\text { net } \\
\text { 3. Child slept under the mosquito } \\
\text { net }\end{array}$ \\
\hline
\end{tabular}

Abbreviations: ANC: antenatal care; BCG: bacillus Calmette- Guérin; DPT: diphtheria, pertussis, and tetanus. The mothers were judged to have access to qualified health services if they could access more domains than the threshold for each health service.

Table 2. Mothers' backgrounds 


\begin{tabular}{|c|c|c|c|c|c|}
\hline \multirow{2}{*}{$\mathrm{Cos}$} & & & & & \\
\hline & Unexposed & Exposed & P-value Unexposed & Exposed & $P$-value \\
\hline$\overline{\mathrm{n}}$ & 1580 & 1649 & 980 & 864 & \\
\hline Age (mean (SD)) & $36.6(8.0)$ & $36.1(8.0)$ & $0.06530 .1(7.0)$ & $29.1(7.0)$ & 0.004 \\
\hline Smoking status (\%) & & & 0.313 & & 0.012 \\
\hline No & $1527(96.6)$ & $1577(95.6)$ & $968(98.8)$ & $837(96.9)$ & \\
\hline Yes & $52(3.3)$ & $70(4.2)$ & $12(1.2)$ & $25(2.9)$ & \\
\hline Education status (\%) & & & $<0.001$ & & $<0.001$ \\
\hline No education & $492(31.1)$ & $406(24.6)$ & $276(28.2)$ & $167(19.3)$ & \\
\hline Primary & $656(41.5)$ & $635(38.5)$ & $442(45.1)$ & $373(43.2)$ & \\
\hline Secondary & $393(24.9)$ & 559 (33.9) & $236(24.1)$ & $297(34.4)$ & \\
\hline Higher & $39(2.5)$ & $49(3.0)$ & $26(2.7)$ & $27(3.1)$ & \\
\hline Urban (\%) & $556(35.2)$ & $963(58.4)$ & $<0.001229(23.4)$ & $407(47.1)$ & $<0.001$ \\
\hline Region of residence (\%) & & & $<0.001$ & & $<0.001$ \\
\hline Aire Metropolitaine/Reste-Ouest & $11(0.7)$ & $796(48.3)$ & $4(0.4)$ & $377(43.6)$ & \\
\hline Artibonite & $200(12.7)$ & $71(4.3)$ & $103(10.5)$ & $44(5.1)$ & \\
\hline Camps & $2(0.1)$ & $352(21.3)$ & $0(0.0)$ & $212(24.5)$ & \\
\hline Centre & $183(11.6)$ & $53(3.2)$ & $137(14.0)$ & $30(3.5)$ & \\
\hline Grand'Anse & $126(8.0)$ & $67(4.1)$ & $88(9.0)$ & $46(5.3)$ & \\
\hline Nippes & $157(9.9)$ & $84(5.1)$ & $61(6.2)$ & $25(2.9)$ & \\
\hline Nord & $235(14.9)$ & $27(1.6)$ & $142(14.5)$ & $13(1.5)$ & \\
\hline Nord-Est & $219(13.9)$ & $10(0.6)$ & $152(15.5)$ & $6(0.7)$ & \\
\hline Nord-Ouest & $189(12.0)$ & $44(2.7)$ & $117(11.9)$ & $24(2.8)$ & \\
\hline Sud & $159(10.1)$ & $48(2.9)$ & $109(11.1)$ & $35(4.1)$ & \\
\hline Sud-Est & $99(6.3)$ & $97(5.9)$ & $67(6.8)$ & $52(6.0)$ & \\
\hline Health care decision (\%) & & & 0.094 & & 0.139 \\
\hline By others & $341(21.6)$ & $321(19.5)$ & $274(28.0)$ & $210(24.3)$ & \\
\hline By mother & $947(59.9)$ & $979(59.4)$ & $614(62.7)$ & $558(64.6)$ & \\
\hline Household wealth (\%) & & & $<0.001$ & & $<0.001$ \\
\hline Poor & $727(46.0)$ & $425(25.8)$ & $615(62.8)$ & $288(33.3)$ & \\
\hline Middle & $323(20.4)$ & $483(29.3)$ & $168(17.1)$ & $279(32.3)$ & \\
\hline Rich & $530(33.5)$ & $741(44.9)$ & $197(20.1)$ & $297(34.4)$ & \\
\hline Drinking alcohol (\%) & & & 0.043 & & 0.338 \\
\hline Every day & $8(0.5)$ & $10(0.6)$ & $2(0.2)$ & $3(0.3)$ & \\
\hline Time to time & $58(3.7)$ & $50(3.0)$ & $13(1.3)$ & $18(2.1)$ & \\
\hline Rarely & $250(15.8)$ & $328(19.9)$ & $130(13.3)$ & $132(15.3)$ & \\
\hline Never & $1263(79.9)$ & $1260(76.4)$ & $834(85.1)$ & $711(82.3)$ & \\
\hline Mother's occupation (\%) & & & $<0.001$ & & $<0.001$ \\
\hline Not working & $477(30.2)$ & $558(33.8)$ & $409(41.7)$ & $413(47.8)$ & \\
\hline Non-professional & $862(54.6)$ & $937(56.8)$ & $450(45.9)$ & $392(45.4)$ & \\
\hline Agricultural & $181(11.5)$ & $104(6.3)$ & $103(10.5)$ & $40(4.6)$ & \\
\hline Professional & $60(3.8)$ & $50(3.0)$ & $18(1.8)$ & $18(2.1)$ & \\
\hline Father's occupation (\%) & & & $<0.001$ & & $<0.001$ \\
\hline Not working & $14(0.9)$ & $26(1.6)$ & $7(0.7)$ & $9(1.0)$ & \\
\hline Non-professional & $529(33.5)$ & $833(50.5)$ & $284(29.0)$ & $466(53.9)$ & \\
\hline Agricultural & $805(50.9)$ & $482(29.2)$ & $568(58.0)$ & $241(27.9)$ & \\
\hline Professional & $188(11.9)$ & $265(16.1)$ & $85(8.7)$ & $122(14.1)$ & \\
\hline
\end{tabular}


Table 3. Results of difference-in-difference analyses and multivariable logistic regression analyses

Before-After Difference

\begin{tabular}{|c|c|c|c|c|c|c|}
\hline & Unexposed \% (n) & $\begin{array}{c}\text { Exposed \% (n) } \\
25.4 \%(283)\end{array}$ & $\begin{array}{c}\text { Odds ratio }(95 \% \\
\mathrm{CI}) \\
0.95\end{array}$ & $\begin{array}{c}\mathrm{P}- \\
\text { value } \\
0.717\end{array}$ & $\begin{array}{c}\text { Odds ratio }(95 \% \\
\text { CI }) \\
0.96\end{array}$ & $\begin{array}{c}\text { P- } \\
\text { value } \\
0.777\end{array}$ \\
\hline $\begin{array}{l}\text { Family } \\
\text { planning }\end{array}$ & $33.5 \%(413)$ & $25.4 \%(283)$ & $\begin{array}{c}0.95 \\
(0.74-1.24)\end{array}$ & & $\begin{array}{c}0.96 \\
(0.73-1.26)\end{array}$ & \\
\hline Antenatal care & $\begin{array}{c}70.6 \%-65.0 \%(338-562) \\
(-5.6 \%)\end{array}$ & $\begin{array}{c}71.9 \%-65.7 \%(348-644) \\
(-6.2 \%)\end{array}$ & $\begin{array}{c}1.05 \\
(0.74-1.48)\end{array}$ & 0.785 & $\begin{array}{c}0.97 \\
(0.68-1.38)\end{array}$ & 0.857 \\
\hline Delivery care & $\begin{array}{c}47.6 \%-41.1 \%(226-388) \\
(-6.5 \%)\end{array}$ & $\begin{array}{c}49.6 \%-49.6 \%(233-412) \\
(0 \%)\end{array}$ & $\begin{array}{c}1.22 \\
(0.87-1.71)\end{array}$ & 0.244 & $\begin{array}{c}1.30 \\
(0.94-1.79)\end{array}$ & 0.108 \\
\hline Vaccination & $\begin{array}{c}58.9 \%-49.4 \%(279-288) \\
(-9.5 \%)\end{array}$ & $\begin{array}{c}50.4 \%-37.3 \%(235-191) \\
(-13.1 \%)\end{array}$ & $\begin{array}{c}0.87 \\
(0.61-1.24)\end{array}$ & 0.431 & $\begin{array}{c}0.82 \\
(0.57-1.18)\end{array}$ & 0.282 \\
\hline $\begin{array}{l}\text { Malaria } \\
\text { prevention }\end{array}$ & $17.4 \%(266)$ & $21.8 \%(306)$ & $\begin{array}{c}0.86 \\
(0.64-1.16)\end{array}$ & 0.322 & $\begin{array}{l}0.88 \\
(0.65-1.18)\end{array}$ & 0.384 \\
\hline
\end{tabular}

In the adjusted analyses, the covariates included were mothers' age and education status.

\section{Figures}

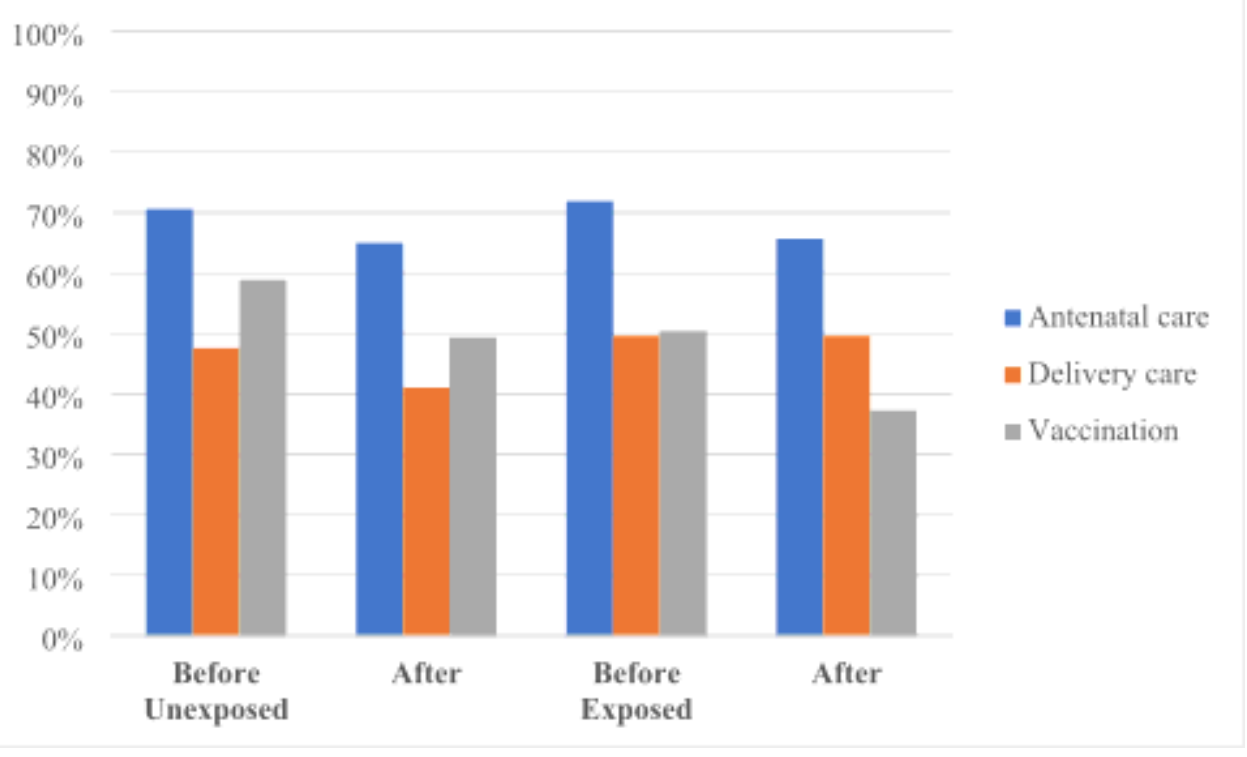

\section{Figure 1}

Percentage of mothers who had access to qualified health services. Legend: Exposed group were those who suffered at least regional or household damage of the earthquake. If the mothers had births after the earthquake, they were categorized as after earthquake group. The bar graph represents the percentages of mothers who could access qualified health services. Family planning and malaria prevention were not listed in the figure because, for those health services, access before the earthquake was not measured. 


\section{Supplementary Files}

This is a list of supplementary files associated with this preprint. Click to download.

- SupplementaryFile.docx 